\title{
Ergenlerin Fiziksel Aktiviteye Kat1lım Durumuna Göre Beden Memnuniyeti ve Sosyal Görünüş Kayg1 Düzeylerinin İncelenmesi ${ }^{1}$
}

\author{
Dilek KANATSIZ² ve Hüseyin GÖKÇE ${ }^{3}$
}

$\ddot{O} z$

Çalışma ergenlerin fiziksel aktiviteye katılım durumuna göre beden memnuniyeti ve sosyal görünüş kayg1 düzeylerinin incelenmesi amacıyla gerçekleştirilmiştir. Ergenlik döneminde ergenin bedeni tartışılmaz ilgi odağı haline gelir. Bu nedenle fiziksel aktiviteye katılım durumunun ergenler üzerinde bedenle ilgili bu iki önemli konuda etkisinin belirlenmesi açısından çalışmanın önemli olduğu düşünülmektedir. Araştırmanın örneklemi; Denizli ili Merkezefendi ve Pamukkale ilçesinde yaşayan Lise öğrenimi gören 14-17 yaş arasındaki kolayda örneklem metoduyla seçilmiş 421 kişi (227 Kadın, 194 Erkek) oluşturmaktadır. Beden memnuniyet düzeyleri Avalos, Tylka ve Wood-Barcalow (2005) tarafindan geliştirilen ve Bakalım ve Taşdelen-Karçkay (2016) tarafından Türkçeye uyarlanan Beden Memnuniyeti Ölçeği ile sosyal görünüş kaygi düzeyleri ile Hart vd. (2008) tarafindan geliştirilen ve Tayfun Doğan (2010) tarafindan Türkçeye uyarlanan Sosyal Görünüş Kayg1 Ölçeği ile ölçülmüştür. Araştırma bulgularına göre; fiziksel aktiviteye katılan ergenlerin, beden memnuniyetlerinin katılmayanlara oranla anlamlı derecede farklı olduğu $(\mathrm{p}<.05)$, fiziksel aktiviteye katılanların ortalamalarının katılmayanların ortalamalarından fazla olmasından kaynaklandığ1 görülmüştür. Sosyal görünüş kaygı puanlarının karşılaştırılmasında ise, fiziksel aktiviteye katılım durumlarına göre anlamlı farklılık oluşturmadığı ancak ortalama puanlara bakıldığında fiziksel aktivitelere katılmayan ergenlerin SGK puanlarının yüksek olduğu görülmüştür. Araştırmanın bir başka probleminde ergenlerin Beden Kitle İndeksine (BMI) göre BMI ve SGK düzeyleri incelenmiş, BMI'lerine göre anlamlı fark bulunmamıștır. SGK ile BMI puanları arasında anlamlı farklılık tespit edilmemisstir. Fiziksel aktiviteye katılan ergenlerin katılmayanlara göre BMI'lerinin anlamlı şekilde yüksek olduğu, SGK düzeyleri arasındaki farkın anlamlı olmadığı; beden kitle indeksine göre ise beden memnuniyeti ve SGK'ları arasında anlamlı bir farkın olmadığı belirlenmiştir.

Anabtar Kelimeler: Ergen, Fiziksel aktivite, Beden memnuniyeti, Sosyal görünüş kayg1s1

\section{Determination of Body Satisfaction and Social Appearance Anxiety Levels According to the Participation of Adolescents in Physical Activity}

\begin{abstract}
The study was conducted to examine the body satisfaction and social appearance anxiety levels of the adolescents according to their participation in physical activity. In adolescence individual's body becomes the focus of indisputable attention. Therefore, it is thought that the study is important in terms of determining the effect of participation in physical activity on these two important issues on the body. The sample of the study selected from the Denizli province, Merkezefendi and Pamukkale district. The instruments conducted to the 421 people (227 women, 194 men) were selected with the sampling method between 13-17 years of age. Body Satisfaction Scale (BSS) which were developed by Avalos, Tylka and Wood-Barcalow (2005) and adapted to Turkish by Bakalım and Taşdelen-Karçkay (2016) and Social Appearance Anxiety Scale (SAAS) developed by Hart etc. (2008) adapted to Turkish bye Tayfun Dogan (2010) were used in study. The data were firstly tested for normality and after the result was positive, T-test in Independent Groups and One-Way Analysis of Variance were used in the analysis of the data. According to the research findings; it is found that, body satisfaction of adolescents participating in physical activity were significantly different from those who did not participate $(\mathrm{p}<.05)$, on the other hand in the comparison of social appearance anxiety scores, there were no significant differences in terms of participation in physical activity. In another problem of the study, Body Satisfaction (BS) and Social Appearance Anxiety (SAA) levels of adolescents were examined according to Body Mass Index (BMI), there is no significant difference between body satisfaction. There was no significant difference between the SAA and BMI scores.
\end{abstract}

Key Words: Adolescent, Physical activity, Body satisfaction, Social anxiety disorder

\section{Atıf İçin / Please Cite As:}

Kanatsiz, D. ve Gökçe H. (2020). Ergenlerin fiziksel aktiviteye katılım durumuna göre beden memnuniyeti ve sosyal görünüş kaygı düzeylerinin incelenmesi. Manas Sosyal Araştırmalar Dergisi, 9(3), 1863-1870.

Geliş Tarihi / Received Date: 25.07.2019

Kabul Tarihi / Accepted Date: 06.01.2020

\footnotetext{
${ }^{1}$ Dr. Öğretim Üyesi - Pamukkale Üniversitesi Spor Bilimleri Fakültesi, hgokce@pau.edu.tr ORCID: 0000-0001-9250-0317

2 Öğrenci - Pamukkale Üniversitesi Spor Bilimleri Fakültesi, dilekkntsz@outlook.com ORCID: 0000-0002-8727-7955
} 


\section{Giriş}

Ergenlik dönemi, duygusal, zihinsel ve sosyal süreçlerinin incelenmesi için önemli bir gelişimsel dönem olarak kabul edilmekle birlikte bu dönem, sosyal etkilerin, yeni bilişsel kapasitelerin ve ortaya çıkan benlik konseptini etkileyeceğine inanılan fiziksel değişimlerin bir sentezini içermektedir (Harter, $1990 \mathrm{~s}$. 207). Birey olma güdüsü, kabul görme isteği ergenlerdeki fiziksel değişikliklere eşlik eden diğer faktörlerdir. Ancak ergenler genellikle ilgi alanları bedenleridir ve bu dönemdeki ergenlerde oluşan değişimler ergen için kusurlar olarak görülmektedir (Harris, 1987). Bu noktada sadece ergenler için değil, yetişkinler için de önemli kavramlar olan beden imajı kavramı gündeme gelmektedir. Beden imajı, hayatımızın bazı noktalarında bizi yönlendiren, iletişimimiz hakkında bize fikirler sunan kendi bedenimiz hakkında oluşturduğumuz düşünceler (Ertürk, 2006, s. 105) bedenimizin ölçüsünü ve şeklini tanımlamaktır (Kurt, Özdilli ve Yorulmaz, 2012 s. 203).

Ergenlik döneminde daha önceki gelişim basamaklarında elde edilmesi beklenen kazanımlar elde edilmeden tutarlı bir kimlik duygusu geliştirmek zordur. Fiziksel aktiviteye (FA) katılımın ergenlerde, doğal olarak kendini anlatma ve kendine güveni artırdığı, başarı ve sosyal iletişim becerilerini geliştirdiği, dayanışma ve centilmenlik ruhunu artırdığı, zihin yorgunluğu ve gerginliği azaltmada yardımcı olduğu düşünülmektedir (Gür ve Küçükoğlu, 1992 s. 16). Bu imajın olumlu olması durumunda, kişiler kendi görünüşlerinin onların kişiliklerinin ve değerlerinin tek belirleyicisi olmadığına düşünürler ve yemek yeme kilo olma gibi konulara odaklanmazlar (Doğan, 2010, s. 151). Olumsuz beden imajına sahip insanlar ise kısaca kişinin diğer bireyler tarafından eleştirilmesi durumunda ortaya çıkmaktadır. Olumsuz beden imajına sahip kişiler diğer bireylere göre kendilerini az çekici bulmaktadır ve bundan dolayı da utanç duymaktadır (Doğan, 2010, s. 151). Bununla birlikte beden memnuniyeti ise özellikle son yllarda incelenmeye başlanan bir kavramdır (Lannantuono ve Tylka, 2012, s. 228). Beden memnuniyeti bireyin var olan beden ölçülerine ve algıladığı kusurlarına rağmen, bedenine ilişskin olumlu bir bakış açısına sahip olması, medyanın sunduğu gerçekçi olmayan idealleri reddederek sağlıklı bir yaşam tarzıyla bedenini koruması ve ona özen göstermesi olarak tanımlanır (Bakalım ve Tadelen-Karçkay, 2016, s. 420).

Dış görünüş bireyler için önemli bir yere sahiptir. Günümüzde de 7 den 70'e herkesin özelliklede gençlerin önemli olarak gördükleri noktalardan biriside diş görünüştür. Bireyler diğer kişiler üzerinde iyi bir izlenim sağlayamayacağını düşündüklerin de kaygı yaşamaktadır (Leary ve Kowalski, 1995, s. 95). Ve bu kayg1 sosyal görünüş kaygısı olarak tanımlanmaktadır. Sosyal görünüş kayg1sı, insanların sosyal ya da performans korkusundan özellikle tanımadığı ya da diğer insanlar tarafindan değerlendirme durumlarında ortaya çıktı̆̆1 görülmektedir (Gautreau, Sherry, Mushquash, Sterwart, 2015, s. 125). İnsanların bedeni ve fiziksel görünüşü ile ilgili oluşturduğu olumsuz düşüncelerin bir sonucu olarak tanımlanmaktadır (Doğan, 2010 , s. 152). Sosyal görünüş kayg1s1; kişinin fiziksel görünüşünün diğer insanlar tarafindan değerlendirildiğinde endişeye düşmesidir ve özellikle ergenlik döneminde görülmektedir. Sosyal görünüş kaygısı olan insanlarda reddedilme korkusundan dolayı daha az samimi davrandıkları gözlenmiştir. Aslında sosyal görünüş kayg1sı, bireylerin kendi bedeni ve görünüssleriyle ilgili düşünmüş olduğu olumsuz fikirlerin bir sonucu olarak yaşandığı söylenebilir (Doğan, 2010, s. 151).

Fiziksel aktivite yaşamımızın tüm dönemlerinde ruhsal, bilişsel ve fiziksel sağlığ1 etkilemektedir (WHO, 2000; Arabacı ve Çankaya, 2007, s. 2). Fiziksel aktivite alışkanlığ1 öncelikle çocukluk döneminde başlar eğer çocukluk döneminde fiziksel aktiviteye katılmıssa bunu yetişkinliğe kadar devam ettirebilir. Bunun için özellikle ailelere büyük sorumluluk düşmektedir, bunun için aileler çocuklarını fiziksel aktiviteye teşvik etmelidir. Düşük FA kalp ve damar hastalıklarının görülmesine sebebiyet vermektedir ve sedanter yaşam tarzının özellikle çocukluk döneminde başladığı bilinmektedir (Memiş ve Yıldıran, 2008, s. 15). Düzenli FA bireylerin sağlıklı büyümesinde ve gelişmesinde önemlidir, özellikle ergenlik döneminde ortaya çıkması olasılığ yüksek olan kötü alışkanlıklar yönelme ve davranışlar sergileme, stres, duygusal ve ruhsal problemler gibi sorunların önüne geçmek ve en aza indirgemekle birlikte ergenlerin fiziksel aktivite ve spor aracıllğıyla sosyalleşmelerini sağlamak; aynı zamanda da yetişkinlik döneminden yaşlılık dönemine giden bu süreci ergenlik döneminde yapılan fiziksel aktivitenin olumlu geri bildirimlerinin kaliteli ve sağllklı bir yaşam için öneminin büyük olabileceği düşünülmektedir (Tavazar vd., 2014, s. 497).

Ergenlik birçok açıdan bireyin değişim ve gelişim dönemidir. Bu dönemin en önemli konularından bir tanesi de bireyin kendi görüntüsünden memnun olup olmaması ve bu durumun tespit edilmesi olası basska sorunların önlenmesi açısından da oldukça önemlidir. Bu gerekçelerle, ergenlerin fiziksel aktiviteye katılım durumuna göre sosyal görünüş kayg1 ve beden memnuniyetlerinin belirlenmesi, amaçlanmıştır. 


\section{Yöntem}

Araştırma deseni, nicel-betimsel yöntem ile hazırlanmıştır. Olgu ve olayları nesnelleştirerek gözlemlenebilir, ölçülebilir ve sayısal olarak ifade edilebilir bir şekilde ortaya koyan bir araştırma türüdür (Arslan, 2012, s. 4). Nicel araştırmanın amacı bireylerin toplumsal davranışlarını gözlem, deney ve test yoluyla nesnel bir şekilde ölçmek ve sayısal verilerle açıklamaktır (Şimşek, 2013, s. 28-29).

\section{Evren - Örneklem}

Araştırmanın evreni Denizli ili Merkezefendi ve Pamukkale ilçelerinde yaşayan Lise öğrenimi gören 13-17 yaş $(\mathrm{x}=16.19)$ arasındaki ergenlerden oluşmaktadır. 13-17 yaş arasındaki ergenlere özel ve kamu okullarından ulaşılmıştır. Bunun için Milli Eğitim Bakanlığı'ndan ve özel kurumlardan izin alınmıştır. Araştırmanın evreni toplam 51.465 lise öğrencisi oluşturmuştur. Örneklem büyüklüğu ise ilk etapta 384 kişi olarak belirlenmiştir (Yazıcıoğlu ve Erdoğan, 2004, s. 40). Ancak 460 lise öğrencisine ulaşılmış, bunlardan ölçme araçlarını eksik dolduranlar ve yaş aralığına uymayanlar araştırma dışı bırakılmıştır. Araştırma örneklemi 421 lise öğrencisinden (227 Kadın 194 Erkek) oluşmuştur. Örnekleme yöntemi olarak kolayda örneklem tekniği kullanılmıştır.

\section{Veri Toplama Araçları}

Kişisel Bilgi Formu. Araştırmacılar tarafından hazırlanan kişisel bilgi formlarında katılımcıların fiziksel aktivite yapıp yapmadığı, boy ve kilosu hakkında bilgileri içermektedir.

Beden Memnuniyeti Ölçeği. Beden memnuniyeti ölçeği Avalos, Tylka ve Wood-Barcalow tarafindan geliştirilmiş ve 2005 yılında yayınlanmıştır. Türkçeye Bakalım ve Taşdelen-Karçkay tarafından 2016 yılında uyarlanmıştır. Toplam 9 maddeden oluşan ölçek 5'li likert tipi ölçek yapisındadır (EK -2). Puanlama, "Hiçbir Zaman (1)", "Nadiren (2)", "Bazen (3)" , "Siklıkla (4)" ve "Her Zaman (5)" ifadelerine göre 1 ile 5 puan arasında puanlanmıştır. Ölçekten elde edilecek en yüksek puan 45 ölçekten elde edilecek en düşük puan ise 9'dur. Uyarlama çalışmalarına baktığımızda Beden Memnuniyeti Ölçeğinin tek faktörlü yapıya sahip olduğu görünmektedir. Beden Memnuniyeti Ölçeğinin geçerlilik ve güvenilirlik çalışması Swami ve diğerleri tarafindan 2015yılında yapılmıştır. Bartlett'in küresellik testi, $\mathrm{x}^{2}(78)=2477.39, \mathrm{p}<.001$ ve KaiserMeyer-Olkin örnekleme yeterliliği ölçüsü KMO = .91, BAS maddelerinin faktör analizi için yeterli ortak varyansa sahip olduğu bulunmuştur. Endekslere dayanarak, varyansın\% 39.7'sini açıklayan Türkiye BAS için tek bir faktör belirlenmiştir. Bu skor için Cronbach's Alfa güvenilirlik kat sayısı .88 olarak bulunmuştur.

Sosyal Görünüs Kaygı Ölçeği. Sosyal görünüş kaygısı ölçeği Hard ve arkadaşları tarafindan (2008) geliştirilmiştir. Ölçek Tayfun Doğan tarafından 2010 yllında uyarlanmışıtır. Toplam 16 maddeden oluşan ölçek 5'li likert tipi ölçek yapısındadır (EK-3). Sosyal görünüş kayg1 ölçeğinde, "Hiç Uygun Değil (1)” " “ Uygun Değil (2)" , “ Biraz Uygun (3)" , “ Uygun (4)" ve "Tamamen Uygun (5)" ifadelerine göre 1 ile 5 puan arasında puanlanmıştır. Ölçekten elde edilecek en yüksek puan 80 ölçekten elde edilecek en düşük puan 16'dır. Ölçeğin kullanım amac1, bireylerin sosyal görünüş kaygılarını ölçmektedir. Sosyal Görünüş Kayg1sı Ölçeğinin puan hesaplaması şu şekildedir: Sosyal görünüş kayg1sı ölçeğin den alınan puan arttıkça, sosyal görünüş kaygısı da artmaktadır. Ölçekten alınan yüksek puanlar görünüş kaygısının yüksek olduğunu göstermektedir. Ölçeğin 1. maddesi tersten kodlanmaktadır. Ölçeğin Türkçe uyarlamasını yapan Tayfun Doğan sosyal görünüş kaygısı ölçeğinin faktör yapısını ortaya çıkarmak için açıklayıcı ve doğrulayıcı faktör analizi yapmıştır. Faktör analizi sonuçlarına baktığımızda ölçeğin özgün formunda olduğu gibi tek boyutlu bir yapıya sahip olduğu görülmektedir. SGKÖ için Cronbach's Alfa iç tutarlık katsayıs1 93, test tekrartest güvenirlik kat sayıs1 .85 ve test yarllama yöntemiyle hesaplanan güvenirlik kat sayıs1.88 olarak bulmuştur. Ölçeğin Türkçe formunun madde-toplam korelasyon kat sayılarının.32 ile.82 arasında olduğu bulunmuştur. Sosyal görünüş kaygisı ölçeği ile Olumsuz Değerlendirilme Korkusu Ölçeği (ODKÖ) arasında .60 ilişki olduğu bulunmuştur. Ölçeğin iç tutarlılık katsayısı üç örneklem için sırasıyla $.94, .95$ ve .94 olarak bulmuştur. Bir ay arayla iki kez uygulama sonucu elde edilen test-tekrar test güvenirlik katsayıs1 ise .84 olarak bulmuştur. Ölçeğin güvenirliği iç tutarlık (Cronbach's Alfa), test tekrar test ve test yarllama yöntemleriyle hesaplanmıştır.

\section{Verilerin Analizi}

Araştırmaya katılan bireylerin beden memnuniyeti toplam (BMÖ), sosyal görünüş kaygısı (SGKÖ) toplam puanları hesaplanmıştır. Öncelikle verilerin normal dağılım gösterip göstermediğine karar vermek için çarpıklık ve basıklık değerleri incelenmiştir. Dağılımın +- 1,5 aralığında olmasına bağlı olarak normallik 
Ergenlerin Fiziksel Aktiviteye Katılım Durumuna Göre Beden Memnuniyeti ve Sosyal Görünüş Kaygı Düzeylerinin Incelenmesi

koşulunun sağlandığına karar verilmiştir (Tabachnick ve Fidell, 2013, s. 952 ). Verilerin normal dağılımına ilişkin çarpıklık ve basıklık değerleri Tablo1'de görülmektedir. Verilerim analizinde beden memnuniyeti ve sosyal görünüş kaygısı arasında ilişkiyi belirlemek için Person Korelasyon Analizi kullanılmıştır. Ergenlerin fiziksel aktiviteye katılım durumlarında göre beden memnuniyetleri ve sosyal görünüş kayg1 düzeyleri bağımsız gruplarda t-Testi ile incelenmiştir. Ergenlerin beden kitle indeksine göre beden memnuniyeti ve sosyal görünüş kaygı düzeylerini belirlemek için ise ANOVA testi kullanılmıştır.

\section{Bulgular}

Araştırmaya katılan öğrencilerden elde edilen verilere ait bulgular aşağıda tablolar halinde verilmiştir. Ergenlerin fiziksel aktiviteye katılım durumuna göre beden memnuniyeti ve sosyal görünüş kayg1 düzeylerinin normal dağılıp dağılmadığına ilişkin çarpıklık ve basıklık değerleri Tablo 1.'de gösterilmiştir.

Tablo 1. Tanımlayıcı Değerler Tablosu

\begin{tabular}{lccccc}
\hline & $\mathbf{n}$ & $\mathrm{X}$ & Ss & Basıklık & Çarp1kl1k \\
\hline Beden Memnuniyeti & 421 & 34.99 & 7.87 & 0.119 & 0.237 \\
Sosyal Görünüş & 421 & 33.44 & 1.35 & 0.119 & 0.237 \\
\hline
\end{tabular}

Tablo 1'de değişkenlerden elde edilen puanların normal dağılım gösterip göstermediğini test etmek için Skewneses Kurtosis değerlerine bakılmış çıkan değerlerim +- 1,5 arasında olmasından dolayı (Tabachnick ve Fidell, 2013, s. 952) veriler normal kabul edilmiştir.

Tablo 2. Beden Memnuniyeti ve Sosyal Görünüs Kaygısı tanımlayıcı Değerleri

\begin{tabular}{lccc}
\hline & $\mathbf{X}$ & Ss & $\mathbf{n}$ \\
\hline Beden Memnuniyeti & 34.99 & 7.87 & 421 \\
Sosyal Görünüş & 33.44 & 13.50 & 421 \\
\hline
\end{tabular}

Tablo 2.1 Beden Memnuniyeti ve Sosyal Görünüs Kaygısı Person Korelasyon Analizi

\begin{tabular}{cc}
\hline $\mathbf{n}=421$ & Sosyal Görünüş Kayg1s1 \\
\hline Beden Memniyeti & $-0.417^{*}$ \\
\hline
\end{tabular}

${ }^{*} \mathrm{p}<0.05$ (2-tailed)

Tablo 2.1'de görüldüğü gibi ergenlerin beden memnuniyeti ve sosyal görünüş kayg1sı arasında korelasyon belirlenmiştir. Beden memnuniyeti ile sosyal görünüş kayg1sı arasında negatif yönde orta seviyede anlamlı ilişki vardır.

Tablo 3. Ergenlerin Fiz̨iksel Aktiviteye Katılım Durumlarna Göre Beden Memnuniyeti ve Sosyal Görünüs Kaygı Düzeylerinin Tanmlaync Değerleri

\begin{tabular}{|c|c|c|c|c|c|c|c|}
\hline & FA Katılım & $\mathbf{n}$ & $\mathrm{X}$ & Ss & $\mathbf{t}$ & sd & $\mathrm{p}$ \\
\hline \multirow{2}{*}{ Beden Memnuniyeti } & Kat1liyor & 224 & 4.00 & 0.79 & 2.870 & 419 & $.004^{*}$ \\
\hline & Katılmiyor & 197 & 3.75 & 0.94 & & & \\
\hline \multirow{2}{*}{ Sosyal Görünüş Kaygısı } & Katıliyor & 224 & 2.15 & 0.76 & -0.915 & 419 & .361 \\
\hline & Katılmiyor & 197 & 2.22 & 0.82 & & & \\
\hline
\end{tabular}

${ }^{*} \mathrm{p}<0.05$

Tablo 3'e bakıldı̆̆ında fiziksel aktiviteye katılan ergenlerin, beden memnuniyetinin katılmayanlara oranla anlamlı düzeyde farklı olduğu görülmüştür. Fiziksel aktiviteye katılanların ortalamalarının katılmayanların ortalamalarından fazla olduğu görülmektedir. Sosyal görünüş kaygı puanlarının karşılaştırılmasında ise, fiziksel aktiviteye katılım durumlarına göre anlamlı farklılık oluşturmadığı ancak ortalama puanlara bakıldığında fiziksel aktiviteye katılmayan ergenlerin sosyal görünüş kayg1 puanlarının yüksek olduğu görülmüştür.

Tablo 4. Ergenlerin Beden Kitle Indeksine Göre Beden Memnuniyeti ve Sosyal Görünüs Kaygı Düzeylerinin Frekans, Ortalama ve Standart Sapma Değerleri

\begin{tabular}{llccc}
\hline & Beden Kitle İndeksi & n & X & Ss \\
\hline Beden & Zayıf & 78 & 35.23 & 7.54 \\
Memnuniyeti & Normal & 288 & 35.24 & 7.72 \\
Toplam Puan & Fazla Kilolu & 55 & 33.38 & 9.00 \\
\hline Sosyal Görünüş & Zayıf & 78 & 34.20 & 13.22 \\
Kaygisı & Normal & 288 & 33.42 & 13.87 \\
Toplam Puan & Fazla Kilolu & 55 & 32.50 & 11.99 \\
\hline
\end{tabular}


Tablo 4'e bakıldığında en yüksek beden memnuniyetinin normal beden indeksine sahip bireylerde olduğu görülmektedir. Sosyal görünüş kaygısında en yüksek beden indeksi zayıf bireylerde olduğu görülmektedir.

Tablo 4. 1 Ergenlerin Beden Kitle İndeksine Göre Beden Memnuniyeti Ve Sosyal Görünüs Kayg Dǚrylerinin ANOVA Sonuclar

\begin{tabular}{|c|c|c|c|c|c|c|}
\hline & $\begin{array}{l}\text { Varyansın } \\
\text { Kaynağ1 }\end{array}$ & $\begin{array}{l}\text { Kareler } \\
\text { Toplamı }\end{array}$ & sd & $\begin{array}{l}\text { Kareler } \\
\text { Ortalamas1 }\end{array}$ & $\bar{F}$ & $p$ \\
\hline \multirow{3}{*}{$\begin{array}{l}\text { Beden } \\
\text { Memnuniyeti }\end{array}$} & Gruplarası & 165.184 & 2 & 82.592 & 1.332 & .265 \\
\hline & Gruplariçi & 25909.814 & 418 & 61.985 & & \\
\hline & Toplam & 26074.998 & 420 & & & \\
\hline \multirow{3}{*}{$\begin{array}{l}\text { Sosyal Görünüş } \\
\text { Kayg1 }\end{array}$} & Gruplararas1 & 93.421 & 2 & 46,710 & .255 & .775 \\
\hline & Gruplariçi & 76466.627 & 418 & 182,935 & & \\
\hline & Toplam & 76560,048 & 420 & & & \\
\hline
\end{tabular}

$*_{\mathrm{p}}<0.05$

Tablo 4.1'deki sonuçlara göre ergenlerin beden kitle indeksine bakımında beden memnuniyetleri arasındaki anlamlı fark olmadığı görülmektedir. Ergenlerin beden kitle indeksi bakımından sosyal görünüş kaygı̈ düzeyleri arasında anlamlı fark olmadığı görülmüştür.

\section{Tartı̧̧ma, Sonuç ve Öneriler}

Araştırmanın birinci problemi ergenlerin fiziksel aktiviteye katılım durumuna göre beden memnuniyeti ile sosyal görünüş kaygı düzeyleri arasında istatistiksel olarak anlamlı bir fark olup olmadığıdır. Bu problem çerçevesinde araştırmanın örneklemini oluşturan ergenlerin fiziksel aktiviteye katılım durumlarına göre beden memnuniyeti düzeylerinin toplam puanları incelendiğinde istatistiksel olarak anlamlı fark olduğu görülmüştür. Fiziksel aktiviteye katılan ergenlerin beden memnuniyeti fiziksel aktiviteye katılmayan ergenlerin beden memnuniyetinden anlamlı düzeyde yüksektir. Polat (2014, s. 73) yapmış olduğu çalışmada egzersiz yapıp yapmama durumuna göre yapılan analizde beden memnuniyeti puan ortalamalarına göre gruplar arası farkın istatistiksel olarak anlamlı olduğu görülmektedir. Farkın hangi gruplardan kaynaklandığını belirlemek için egzersiz yapan ve yapmayan gruplar birbirleriyle karşılaştırıllmış, egzersiz yapanların yapmayanlara göre daha yüksek beden memnuniyetine sahip oldukları görülmüştür. Johnson, Harris ve Burton (2013 s. 163) yaptı̆̆ çalışmada beden memnuniyeti, kısa ( $>6$ ay) ve uzun süreli (> 5 yll) fiziksel aktivitenin sürdürülmesinin Transtestik Modelle ilişkili olduğunu belirlemiştir. Literatüre bakıldığında çalışmadaki bulgularla tutarllık göstermektedir.

Araştırmanın örneklemini oluşturan ergenlerin fiziksel aktiviteye katılım durumuna göre sosyal görünüş kayg1 düzeylerinin toplam puanları incelendiğinde istatiksel olarak anlamlı fark olmadığına rastlanmıştır. Ancak ortalama puanlar bakıldığında fiziksel aktiviteye katılmayan ergenlerin sosyal görünüş kaygısı puanlarının yüksek olduğu görülmektedir. Alemdağ ve Öncü'nün $(2015$, s. 297) yapmış olduğu çalışmaya baktığımızda öğrencilerin fiziksel aktiviteye katılım durumu ve sosyal görünüş kaygisı arasında anlamlı bir ilişki olduğu görülmektedir. Öğrencilerin fiziksel aktiviteye katılım durumlarıyla sosyal görünüş kaygıları arasındaki ilişkinin negatif yönde, istatiksel olarak anlamlı bir ilişki olduğu görülmektedir. Bu durumda fiziksel aktiviteye katılan öğrencilerin görünüş kaygisının düşük olduğunu göstermektedir. Soylu , Atik ve Öcalan (2017, s. 42) ergenler üzerinde yapmış olduğu çalısmaya baktı̆̆ımızda spor yapanlar ile spor yapmayanların sosyal görünüss kaygı düzeyleri arasında anlamlı fark olduğu görülmektedir. Farkın hangi gruptan kaynaklandığını baktığımızda spor yapan ergenlerin, spor yapmayanlara göre daha yüksek sosyal görünüss kaygısına sahip oldukları görülmektedir. Vatansever (2017, s. 109) yaptığı çalışmada 14-18 yaş aralığındaki ergenlerin spor yapma durumuna göre sosyal görünüş kaygisı arasında istatiksel olarak anlamlı fark olduğu görülmektedir. Spor yapan ergenlerin sosyal görünüş kaygılarının, spor yapmayan ergenlere göre daha düşük olduğunu görülmektedir. $\mathrm{Bu}$ üç çalışmada yapmış olduğumuz çalışmayla tutarlılık göstermektedir.

Araştırmanın ikinci probleminde beden memnuniyeti ve sosyal görünüş kaygısı ile beden kitle indeksi değişkenine göre istatiksel olarak anlamlı farkın olup olmadığıdır. Bu problem çerçevesinde araştırmanın örneklemini oluşturan bireylerin beden memnuniyeti düzeylerinin beden kitle indeksine göre toplam puanlar incelendiğinde istatiksel olarak anlamlı fark olmadığı görülmüştür. Kantanista vd. (2015 s. 40) çalışmasında BMI erkeklerle karşılaştırıldığında kızlardan daha fazla beden memnuniyetine sahip olduğu görülmüştür. Austin vd. (2009, s.1) yaptığı çalışmada, kızlarda BKI arttıkça zayıf beden memnuniyetinde 
bir artış gözlemlemiştir. Bununla birlikte, erkekler arasında düşük BKI‘li erkeklerin ve yüksek BKI’li erkeklerin daha yüksek düzeyde beden memnuniyeti bildirdiği gözlemlenmiştir.

Araştırmanın örneklemini oluşturan bireylerin sosyal görünüş kaygı düzeylerinin beden kitle indeksi faktörüne göre toplam puanları incelendiğinde istatiksel olarak anlamlı fark olmadığına rastlanmıştır. Ancak ortalamalara bakıldığında şişman beden kitle indeksine sahip ergenlerin sosyal görünüş kaygısın yüksek olduğu görülmektedir. Erdoğan'ın (2018, s. 89) yapmış olduğu çalışmada sosyal görünüş kaygisı ve BMI arasında istatiksel olarak anlamlı ilişki bulmadığı görülmüştür. Meral (2018, s. 93) yaptığı çalışmada üniversite öğrencilerinin beden kitle indeksiyle sosyal görünüş kaygısı arasında anlamlı iliş̧ki bulamadığ1 görülmektedir. Yapılan bu araştırmaya benzer bir çalışsmayı Mülazımoğlu ve Aşçı (2006, s. 16) yapmıştır. Mülazımoğlu ve Aşçı (2006, s. 16) çalışmalarında 14-25 yaş grubu öğrencilerin sosyal fizik kaygının geçerlilik ve güvenilirliğine bakmışlardır ve sonuç olarak da Sosyal Fizik Kaygı Envanteri’nin 14-25 yaş grubu öğrencilerin sosyal fizik kaygı düzeyini ölçmek için geçerli ve güvenilir olduğunu belirlemişlerdir.

Sonuç olarak, Fiziksel aktivitenin ergen bireylerde beden memnuniyeti üzerinde anlamlı farklılık oluşturacak bir faktör olduğu $(\mathrm{p}<0.05)$. Sosyal görünüş kaygısının ise fiziksel aktiviteye katılım durumuna göre değişmediği görülmektedir. Beden kitle indeksi beden memnuniyeti ve sosyal görünüş kayg1 üzerinde anlamlı farklılık oluşturacak bir faktör olmadığ1 görülmektedir. Beden memnuniyeti ve sosyal görünüş kayg1 arasında negatif yönde orta derecede bir ilişki olduğu görülmektedir.

$\mathrm{Bu}$ çalışmaya verilebilecek öneriler, veliler ve eğitim alanındaki bireylerin fiziksel aktivite programlarını ergenlerin problemlerinin çözümünde bir araç olarak kullanma konusunda bilgilendirmesi ve cesaretlendirmesi gerekmektedir. Beden memnuniyeti konusunda problemi olan kişilerin fiziksel aktivite programlarını katılmaları için özel programlar hazırlanabilir.

\section{Etik Beyan}

"Ergenlerin Fiæilksel Aktiviteye Katılm Durumuna Göre Beden Memnuniyeti ve Sosyal Görünüs Kaygz Düzeylerinin Incelenmesi" başı1ılı çalışmanın yazım sürecinde bilimsel, etik ve alıntı kurallarına uyulmuş; toplanan veriler üzerinde herhangi bir tahrifat yapılmamış ve bu çalışma herhangi başka bir akademik yayın ortamına değerlendirme için gönderilmemiştir.

\section{Kaynakça}

Alemdağ, S. ve Öncü, E. (2015). Öğretmen adaylarının fiziksel aktiviteye katıllım ve sosyal görünüş kaygııının incelenmesi. Special Issue, 3, 287-300. doi: 10.14486/IJSCS291

Arabacı, R. ve Çankaya, C. (2007). Beden eğitimi öğretmenlerinin fiziksel aktivite düzeylerinin araştırılması. Uludağ Üniversitesi Eğitim Fakilltesi Dergisi, 20(1), 1-15. Erişim adresi: http://kutuphane.uludag.edu.

Arslan, R. ve Ökten, A. (1994). Araştrma yöntemleri. İstanbul: YTÜ Mimarllk Fakültesi Baskı İşliği.

Austin, B., Hines, J. ve Veugelers, P. J. (2009). Body satisfaction and body weight: Gender differences and sociade mographic determinants. BMC PublicHealth, 1-7. doi: 10.1186/1471-2458-9-313

Avalos, L., Tylka, T. L. ve Wood-Barcalow, N. (2005). The body appreciation scale: development and psychometric evaluation. Body Image, 2, 285-297. doi: 10.1016/j.bodyim.2005.06.002

Bakalım, O. ve Taşdelen-Karçkay, A. (2016). Beden memnuniyeti ölçeği: Türk kadın ve erkek üniversite öğrencilerinde faktör yapısı ve psikometrik özelliklerinin değerlendirilmesi. Mersin Üniversitesi Eğitim Fakïltesi Derneği, 12(1), 410-422. doi: 10.17860/efd.38032

Doğan, T. (2010). Sosyal görünüş kayg1sı ölçeğinin Türkçe uyarlaması: geçerlilik ve güvenilirlik çalsşması. Hacettepe Üniversitesi Eğitim Fakültesi Dergisi, 39, 151-159. Erişim adresi: https://dergipark.org.tr/

Erdoğan, İ. (2018). Üniversite ögrencilerinde sosyal görïnüs kayglss ve yeme tutumu arasindaki iliskkinin incelenmesi (Yüksek Lisans Tezi). Üsküdar Üniversitesi Sosyal Bilimler Enstitüsü, İstanbul.

Ertürk, D.Y. (2006). Bedenin iki yanması: Bedenle iletişim, iletişimde beden. İletişim Fakültesi Dergisi, 24. Erişim adresi: https://dergipark.org.tr

Gautreau, C. M., Sherry, S. B., Mushquash, A. R. ve Stewart, S. H. (2015). Is self-critical perfectionism an antecedent of or a consequence of social anxiety, or both? A 12-month, three-wave longitudinal study. Personality and Individual Differences, 82, 125-130. https://doi.org/10.1016/j.paid.2015.03.005

Gür, H. ve Küçükoğlu, S. (1992). Yaşhllk ve firiciksel aktivite. Bursa: Roche Yayınları.

Harris, D. V. (1987). The female athlete. In J. R. May ve M. J. Asken (Edt.). Sport psychology: The psychological health of the athlete. New York: Pma, 99166.

Hart, T. A. Flora, D. B. Palyo, S. A. Fresco, D. M. Holle, C. ve Heimberg, R. C. (2008). Development and examination of the social appearance anxiety scale. Assessment, 15, 48-59. Doi: 10.1177/1073191107306673

Harter S. (1990). Processes underlying adolescent self-concept formation. In R. Montemayor, G. R. Adams, R. Gerald, T. P. Gullota (Edt.). From cbildhood to adolescence: A transitional period advances in adolescent development. ThousandOaks, California: Sage Publications. 
Johnson, P., Fallon, E., Harris, B. S. ve Burton, B. (2013). Body satisfaction is associated with transtheoretical model constructs for physical activity behavior change. Body Image, 10(2), 163-174. Doi: 10.1590/S010305822011000200013

Kantanista, A. Osinski, W. Borowiec, J. Tomczak, M. Krol-Zielinska, M. (2015). Body image, BMI, and physical activity in girls and boys aged 14-16 Years. Body Image, 15, 40-43.

Kurt, E., Özdilli, K. ve Yorulmaz, H. (2013 ). Body Image and Self-Esteem in PatientswithRheumatoidArthritis. Archivesof Neuropsychiatry, 50, 202-208.

Lannantuono, A. C. ve Tylka, T. L. (2012). Interpersonal and intrapersonal links to body appreciation in college women: An exploratory model. Body Image, 9, 227-235. doi:10.1016/j.bodyim.2012.01.004

Leary, M. R. ve Kowalski, R. M. (1995). The self-presentation model of socialphobia. In R. G. Heimberg, M. R. Liebowitz, D. A. Hope ve F. R. Schneier (Edt.). Social phobia: Diagnosis, assessment and treatment. New York: Guilford Press. pp. 94-112

Memiş, U. A. ve Yıldıran, İ. (2008). Çocukluk ve ergenlikteki fiziksel aktivite deneyimleri ile yetişkinlikteki fiziksel aktivite düzeyleri arasındaki ilişki. Gaz̨i Beden Eğitimi ve Spor Bilimleri Dergisi, 13(1), 13-32. Erişim adresi: https://dergipark.org.tr/tr/pub/gbesbd/issue/28040/297773

Meral B. S. (2018). Üniversite ögrencilerinde sosyal görünüs kaygısı ile algilanan sosyal destek arasindaki ilișkinin incelenmesi (Yüksek Lisans Tezi). Üsküdar Üniversitesi Sosyal Bilimler Enstitüsü, İstanbul.

Mülazımoğlu-Ballı, Ö. Aşçı, F.H. (2006). Sosyal fiziksel kaygı envanterinin geçerlilik ve güvenilirlik çalışması. Spor Bilimleri Dergisi, 17: 11-19. Erişim adresi: https://dergipark.org.tr/tr/download/article-file/151337

Polat, G. (2014). Düzenli egžersiz yapan kadinlarda egzersiz̨in benlik saygisı ve beden memnuniyeti üzerine etkisi (Yüksek Lisans Tezi). Kahramanmaraş Sütçü İmam Üniversitesi Sağlık Bilimleri Enstitüsü, Kahramanmaraş: s 73.

Soylu, Y., Atik, F. ve Öçalan, M. (2017). Ergenlerin Sosyal Görünüş Kayg1sı Düzeylerinin İncelenmesi. Sportif Bakış: Spor ve Eğitim Bilimleri Dergisi, SI(1), 38-45. Erişim adresi: https://dergipark.org.tr/tr/download/articlefile/392182

Şimşek, A. (2013). Sosyal bilimlerde nitel ve nicel araştırma. DergiPark, 28-29.

Türkiye İstatistik Kurumu. (2012). Faaliyet raporu: 2012 y1l. Erişim adresi http://www.tuik.gov.tr/HbPrint.do?id=13458.

Tabachnick, B. G. \&Fidell, L. S. (2013). Using multivariate statistics (6th ed.), Boston: Allynand Bacon.

Tavazar, H., Erkaya, E., Yavaşı, Ö., Tez, Ö., Zerengök, D., Güzel, P. ve Özbey, S. (2014). Lise eğitimi alan genç erişkinlerin fiziksel aktivite ve yaşam kalitesi arasındaki farkllıklarının incelenmesi (Manisa ili örneği). International Journal of Science Culture and Sport, 2(1), 496-10. Doi: 10.14486/IJSCS122

Vatansever, S. (2017). Lisansh spor yapan ve yapmayan ergenlerin mental iyi olus, benlik saygisı, sosyal görünüs kaygisı ve algilanan sosyal destek açısından karşılaştırılması (Yüksek Lisans Tezi). İstanbul Arel Üniversitesi Sosyal Bilimler Enstitüsü, İstanbul: s109. Erişim adresi: https://hdl.handle.net/20.500.12294/1181

WHO-World HealthOrganization. (2000). Obesity: preventing and managing the global epidemic (No. 894). World HealthOrganization.

Yazıcıŏglu, Y. ve Erdoğan, S. (2004). Spss uygulamal bilimsel araștırma yöntemleri. Ankara: Detay Yayıncılık

\section{EXTENDED ABSTRACT}

The adolescence period is regarded as an important developmental period for the examination of mental and social processes and this period includes the synthesis of physical changes that are considered to affect the social effects, new cognitive capacities and emerging self-concept (Harter, 1990, p. 207). The interest area of adolescents is usually their body and the changes in this period are regarded as defects in their point of view (Harris, 1987, p. 163). At this point, the concept of body image which is an important concept comes up. Body image defines the opinions we create about our body that lead us in a certain point of our lives and present us ideas about our communication (Ertürk, 2006, p. 105) and the size and shape of our body (Kurt, Özdilli, \& Yorulmaz, 2012 p. 203). In addition to these, the concept of body satisfaction appears which is started to be examined in recent years. Body satisfaction is defined as having a positive opinion about one's body despite the body sizes and the flaws that individuals perceive by rejecting the unrealistic ideals that are presented by the media and protecting and caring their body with a healthy lifestyle (Bakalım, \& Tadelen-Karçkay, 2016, p.420). Appearance is important for individuals. When individuals believe that they could not leave a good impression on other people, they feel anxious (Leary and Kowalski, 1995, p. 95). This anxiety is defined as social appearance anxiety. It is observed that social appearance anxiety emerges from the social or performance fear in situations where individuals are evaluated by other people, especially by the people that don't know them (Gautreau, Sherry, Mushquash, \& Sterwart, 2015 p. 125). Physical activity affects the mental, cognitive and physical health throughout our lives (WHO, 2000; Arabac1, \& Çankaya, 2007, p. 2). Adolescence is a period of change and development of an individual in many aspects. One of the most important subjects of this stage is whether or not individuals are satisfied with their appearance and determining this situation is quite important in terms of preventing the other probable problems. For these reasons, it was aimed to determine the social 
appearance anxiety and body satisfaction of adolescents according to their participation status to PA. The research was prepared with the quantitative-descriptive method. The population of the research consists of adolescents in the age group of 13-17 ( $\mathrm{x}=16.19)$, studying in high-school and living in the Merkezefendi and Pamukkale districts of Denizli province. The adolescents in the age group of 13-17 were reached through private and public schools. Permission was taken from The Ministry of National Education and private institutions. The population of the research consists of 51,465 high school students. The sample was determined as 384 students at first (Yazıcıoğlu, \& Erdoğan, 2004, p. 40). However, 460 high school students were reached and among them, students who did not fill the scale tools completely and did not comply with the age group were excluded. The sample of the research consists of 421 high school students (227 Females, 194 Males). Convenience sampling method was used as the sampling method. Personal information form which was developed by the researcher was used in the research. Body Satisfaction Scale was used in the research which was developed by Avalos, Tylka and Wood-Barcalow, published in 2005 and adapted to Turkish in 2016 by Orkide Bakalım and Arzu Taşdelen-Karçkay. Social Appearance Anxiety Scale which is another scale that was used was developed by Hard et al. (2008). The Scale was adapted to Turkish by Tayfun Doğan in 2010. For the analysis of the data, total scores of body satisfaction (BSS) and social appearance anxiety (SAAS) of the participants were calculated. Skewness and kurtosis values were examined in order to decide whether or not the data show normal distribution. It was decided that the normality condition was provided since the distribution was between +-1.5 (Tabachnick, \& Fidell, 2013, p. 952). In the analysis of the data, the Pearson Correlation Analysis was used in order to determine the relationship between body satisfaction and social appearance anxiety. The levels of body satisfaction and social appearance anxiety according to the participation status of adolescents to the physical activity was examined with T-test in independent groups. ANOVA test was used in order to determine the body satisfaction and social appearance levels of adolescents according to their body mass index. The data was applied in SPSS 16.0 program. According to the findings of the research, when the relationship between body satisfaction and social appearance anxiety is examined, a negative medium significant relationship was determined. When the body satisfaction and social appearance scores are examined according to the participation status of students to physical activity, it was observed that the body satisfaction of adolescents who participate in physical activity are significantly higher than those who don't. It can be observed that the averages of students who participate in physical activity are higher than the averages of those who don't. In the comparison of social appearance anxiety scores, it was observed that there wasn't a significant difference according to the participation status of students to physical activity, however, when the average scores were examined, it was observed that the social appearance anxiety scores of adolescents who don't participate in physical activity were high. When the body satisfaction and social appearance anxiety scores were examined according to the body mass index, it can be observed that there wasn't a significant difference between the body mass index and body satisfaction of adolescents. It was observed that there wasn't a significant difference between the body mass index and social appearance anxiety levels of adolescents. 